\title{
QUALIDADE FÍSICO-QUÍMICA E MICROBIOLÓGICA DA ÁGUA DE CONSUMO HUMANO E ANIMAL DO BRASIL: ANÁLISE SISTEMÁTICA
}

\author{
Cynthia de Freitas Birkheuer ${ }^{1}$, Juliana de Araujo ${ }^{2}$, Claudete Rempel ${ }^{3}$, \\ Mônica Jachetti Maciel ${ }^{4}$
}

Resumo: A água é o recurso natural mais importante do planeta, e encontra-se suscetível às alterações causadas por contaminantes biológicos e químicos, podendo causar doenças tanto no homem, como em animais. Este trabalho objetivou quantificar pesquisas bibliográficas referentes à qualidade físicoquímica e microbiológica da água destinada ao consumo humano e animal, afim de analisar se estão dentro dos padrões exigidos pelas legislações vigentes. As pesquisas foram realizadas em duas bases de dados científicas, a Coordenação de Aperfeiçoamento de Pessoal de Nível Superior (Capes) e o Scientific Electronic Library Online (SciELO). A quantificação dos dados partiu da análise de 7.865 artigos, destes, 27 foram selecionados pela leitura dos títulos, sendo que 8 eram repetições, restando 19 produções. Em seguida, fez-se a leitura dos resumos, restando 11 artigos e por fim, selecionou-se 8 de interesse. Por meio dos artigos analisados, pode-se perceber que existem poucas pesquisas em relação a qualidade físicoquímica e microbiológica das águas destinadas ao consumo humano e, principalmente, animal. A partir desta investigação, conclui-se que a maioria dos valores das águas brasileiras analisadas encontravam-se fora do qual é estipulado pelas Resoluções e Portarias vigentes.

Palavras-chave: Microrganismos. Água potável. Dessedentação animal.

1 Acadêmica do Curso de Ciências Biológicas e aluna de Iniciação Científica, Univates, Lajeado/RS, Brasil.

2 Acadêmica do Curso de Engenharia Química, Univates, Lajeado/RS, Brasil.

3 Professora doutora do Centro de Ciências Biológicas e da Saúde (CCBS), do Programa de Pós-Graduação em Ambiente e Desenvolvimento (PPGAD) e do Programa de PósGraduação em Sistemas Ambientais Sustentáveis (PPGSAS) Univates, Lajeado/RS, Brasil.

4 Professora doutora do Centro de Ciências Biológicas e da Saúde (CCBS) e do Programa de PósGraduação em Sistemas Ambientais Sustentáveis (PPGSAS) Univates, Lajeado/RS, Brasil. 


\title{
PHYSICAL-CHEMICAL AND MICROBIOLOGICAL QUALITY OF WATER FOR HUMAN AND ANIMAL CONSUMPTION IN BRAZIL: SYSTEMATIC ANALYSIS
}

\begin{abstract}
Water is the most important natural resource on the planet, and is susceptible to changes caused by biological and chemical contaminants, which can cause diseases in both humans and animals. This work aimed to quantify bibliographical research concerning the physical-chemical and microbiological quality of water intended for human and animal consumption, in order to analyze whether they are within the standards required by current legislation. The research was carried out in two scientific databases, the Coordination for the Improvement of Higher Education Personnel (Capes) and the Scientific Electronic Library Online (SciELO). The quantification of the data was based on the analysis of 7.865 articles, of which 27 were selected by reading the titles, 8 were repetitions, 19 productions remaining, then the abstracts were read, remaining 11 articles and finally selected there is 8 of interest. Through the articles analyzed, it can be seen that there is little research regarding the physical-chemical and microbiological quality of water intended for human consumption, and mainly animal. From this investigation, it is concluded that most of the values of the Brazilian waters analyzed were outside of regulated by the Resolutions and Ordinances in force.
\end{abstract}

Keywords: Microorganisms. Potable water. Animal behavior.

\section{INTRODUÇÃO}

A água é o recurso natural mais importante para a manutenção da vida na terra (BACCI; PATACA, 2008), sendo essencial para a sobrevivência de todos os seres vivos, pois exerce funções fisiológicas relevantes (MAGALHÃES et al., 2014). Por ser o elemento de maior valor biológico, a água serve de veículo para vários agentes bioquímicos que alteram sua função nutricional, deste modo, a população deve estar atenta aos fatores que alteram negativamente a qualidade da água que consomem (ROCHA et al., 2006).

No meio rural, por exemplo, a água é bastante susceptível às diversas alterações, já que o abastecimento hídrico são nascentes e poços artesianos, que normalmente, não possuem o devido cuidado higiênico sanitário (AMARAL et al., 2003), pois muitas vezes encontram-se próximos a áreas de pastagem animal, esterqueiras ou abatedouros (NUNES et al., 2010).

Porém, geralmente as preocupações com a qualidade da água são voltadas ao consumo humano e não à dessedentação dos rebanhos, desse modo, os cuidados com a saúde animal são negligenciados. De acordo com Magalhães et al. (2014), este descuido acarreta no desenvolvimento de doenças que acabam diminuindo a qualidade e a quantidade de produção animal destas propriedades.

Por ser um recurso de fundamental importância para a vida, torna-se imprescindível controlar e exigir sua qualidade, por meio de regulamentos técnicos específicos e legislações que garantem saúde e bem-estar à população humana e animal (MORAIS et al., 2016). Este controle é realizado por intermédio de análises laboratoriais, 
investigando-se a qualidade da água, tanto por ensaios físico-químicos (cor, turbidez, condutividade elétrica, temperatura, $\mathrm{pH}$, alcalinidade, dureza total, ferro, cloretos, oxigênio dissolvido, oxigênio consumido, cloro residual livre, sólidos totais, amônia), quanto por métodos microbiológicos (coliformes totais e termotolerantes e bactérias mesófilas aeróbias), conforme às Resoluções do Conselho Nacional do Meio Ambiente (CONAMA) no 430/2011 (BRASIL, 2011a) e no 396/2008 (BRASIL, 2008) e a Portaria do Ministério da Saúde no 2914/2011 (BRASIL, 2011b).

Para tanto, este trabalho tem como objetivo quantificar pesquisas bibliográficas referentes à qualidade físico-química e microbiológica da água destinada ao consumo humano e animal, afim de analisar se as mesmas encontram-se dentro dos padrões exigidos pelas legislações vigentes.

\section{METODOLOGIA}

Esta pesquisa bibliográfica foi realizada por meio de uma revisão sistemática de artigos científicos sobre a qualidade da água para consumo humano e animal. Foram considerados todos os artigos científicos com até 20 anos de publicação (1997-2017) nos idiomas português, e inglês. As bases de dados utilizadas para esta revisão foram: Coordenação de Aperfeiçoamento de Pessoal de Nível Superior (Capes) e Scientific Electronic Library Online (SciELO). As pesquisas encontradas estavam disponibilizadas com o texto completo e gratuito, mediante do link presente nas bases.

A análise das pesquisas científicas foi dividida em três etapas. $\mathrm{Na}$ primeira, selecionou-se os artigos que correspondiam aos seguintes critérios de inclusão de seleção: títulos dos artigos que abordassem a qualidade físico-química e microbiológica da água para consumo humano e para dessedentação de animais, utilizando-se as seguintes palavras-chaves: "qualidade da água"; "microbiologia da água" e "dessedentação".

$\mathrm{Na}$ segunda etapa, foram selecionados os artigos a partir da leitura dos resumos (para esta seleção foi realizada uma leitura prévia das metodologias presentes como os procedimentos de coletas e análises microbiológicas e físico-químicas) e na terceira e última etapa, foram avaliados os artigos triados anteriormente, realizando-se a leitura completa dos mesmos. Foram então selecionadas as pesquisas científicas em que os autores utilizaram metodologias de coletas de água, análises físico-químicas e microbiológicas semelhantes às estudadas, tais como: condutividade elétrica, temperatura, turbidez, cloro residual livre, sólidos totais dissolvidos, determinação de $\mathrm{pH}$, oxigênio dissolvido, coliformes totais, fecais e termotolerantes e Escherichia coli.

Os artigos selecionados foram salvos em subpastas nomeadas como: "título", salvos os artigos selecionados pela leitura do título, "resumo" armazenados os artigos selecionados a partir da leitura do resumo, e por fim, a subpasta denominada "artigo", no qual foram salvos os periódicos escolhidos a partir da leitura do artigo completo. 
Excluiu-se artigos que apresentavam outros tipos de análises ou metodologias, como por exemplo, a água utilizada para dessedentação de outros tipos de animais que não sejam bovinos, entre outros.

\section{RESULTADOS E DISCUSSÃO}

Esta revisão sistemática partiu, inicialmente, de 7.865 artigos publicados com texto completo nas duas bases de dados (Capes e SciELO), sendo que 7.677 pesquisas foram da base de dados de Periódicos da Capes e 188 no SciELO. Destes, 27 foram selecionados pela leitura dos títulos, sendo que 8 eram repetições, restando 19 produções, em seguida, fez-se a leitura dos resumos, restando 11 artigos, e por fim, selecionou-se 8 de interesse, conforme dados da Figura 1. Os 8 artigos de interesse, representam $0,10 \%$ do total de artigos encontrados nas bases de dados.

Figura 1 - Fluxograma das etapas da seleção dos artigos de interesse

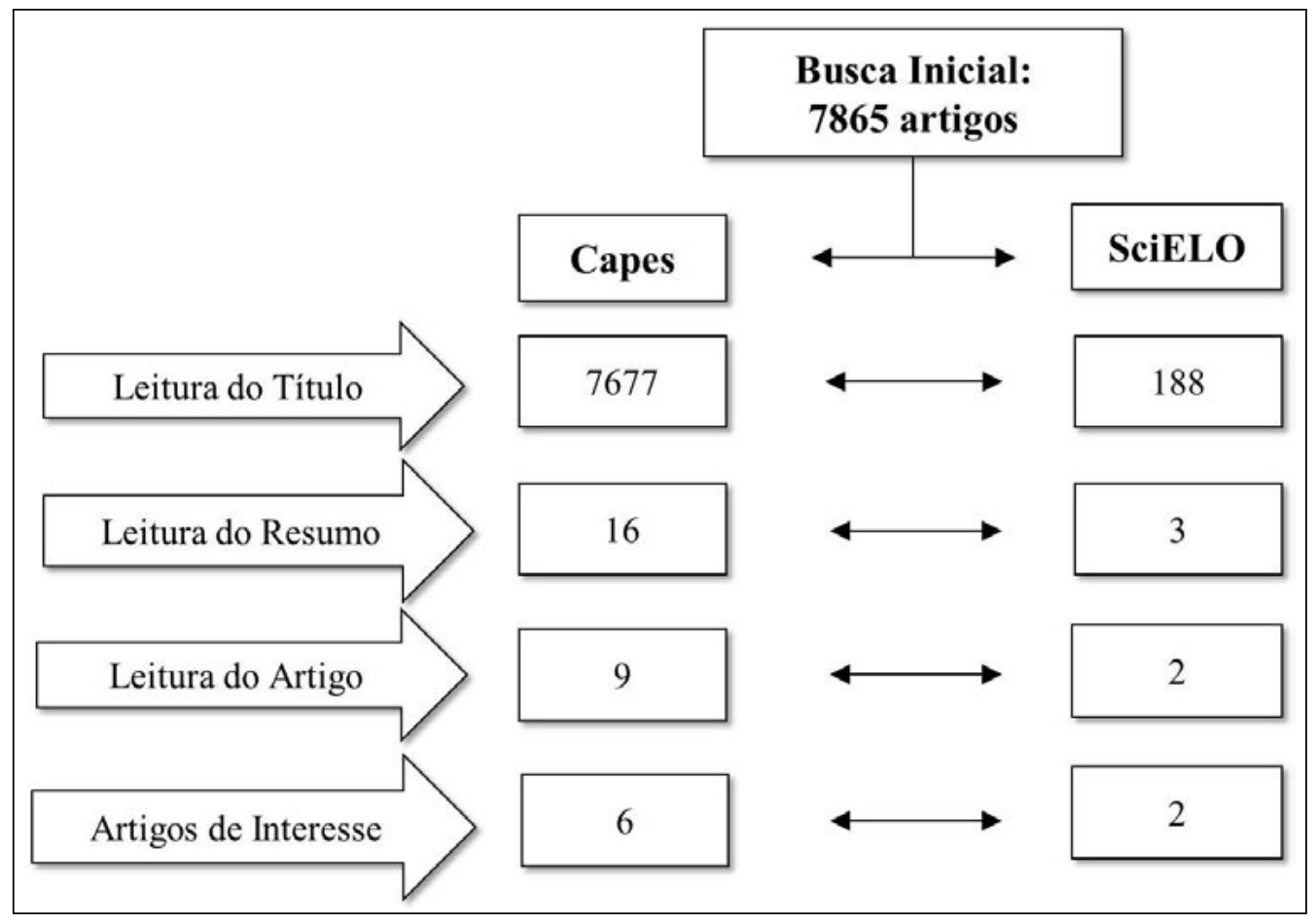

Fonte: Dados da pesquisa, 2017.

A análise das produções de interesse foi realizada inicialmente por meio da construção do quadro sinóptico (QUADRO 1), no qual foram descritas as seguintes variáveis: referência, objetivos, metodologias, resultados, revista, base de dados. 
Nesta etapa da pesquisa os artigos selecionados foram publicados entre os anos de 2002 a 2016. Dois artigos foram publicados nos anos de 2002 e 2016. Já no período de 2003, 2006, 2010 e 2014, quatro foram publicados, um por ano. Em um dos estudos (ROCHA et al., 2006) a investigação foi do período de 1999 a 2000.

\section{Quadro 1 - Apresentação e caracterização dos artigos selecionados}

\begin{tabular}{|c|c|c|c|c|c|}
\hline Título/Referência & Objetivos & Metodologias & Resultados & Revista & $\begin{array}{c}\text { Base de } \\
\text { dados }\end{array}$ \\
\hline $\begin{array}{l}\text { Água de consumo } \\
\text { humano como fator } \\
\text { de risco à saúde em } \\
\text { propriedades rurais } \\
\text { (AMARAL et al., } \\
\text { 2003) }\end{array}$ & $\begin{array}{l}\text { Analisar a qualidade } \\
\text { higiênico-sanitária } \\
\text { da água de consumo } \\
\text { humano em pro- } \\
\text { priedades rurais. }\end{array}$ & $\begin{array}{l}\text { Foram coletadas } 180 \\
\text { amostras de água uti- } \\
\text { lizada para consumo } \\
\text { humano de fontes, } \\
\text { reservatórios e ponto } \\
\text { de consumo em } 30 \\
\text { propriedades rurais, } \\
\text { nos períodos de chuva } \\
\text { e estiagem. Realizou-se } \\
\text { análises para detecção } \\
\text { de coliformes totais e } \\
\text { Escherichia coli. } \\
\end{array}$ & $\begin{array}{l}\text { Os resultados demonstraram } \\
\text { que } 90 \% \text { das amostras de água } \\
\text { das fontes, } 90 \% \text { dos reservató- } \\
\text { rios e } 96,7 \% \text { de água de consu- } \\
\text { mo humano, colhidas no perío- } \\
\text { do de chuvas, e } 83,3 \%, 96,7 \% \text { e } \\
90 \% \text {, daquelas colhidas, respec- } \\
\text { tivamente nos mesmos locais, } \\
\text { durante a estiagem, estavam } \\
\text { fora dos padrões microbiológi- } \\
\text { cos de potabilidade para água } \\
\text { de consumo humano. }\end{array}$ & $\begin{array}{c}\text { Rev. } \\
\text { Saúde } \\
\text { Pública }\end{array}$ & Capes \\
\hline $\begin{array}{l}\text { Análise microbio- } \\
\text { lógica de águas } \\
\text { minerais e de água } \\
\text { potável de abasteci- } \\
\text { mento, Marília, SP } \\
\text { (ALVES; ODORI- } \\
\text { ZZI; GOULART, } \\
\text { 2002) }\end{array}$ & $\begin{array}{c}\text { O objetivo do } \\
\text { estudo foi avaliar } \\
\text { a qualidade mi- } \\
\text { crobiológica da } \\
\text { água potável e de } \\
\text { diferentes marcas } \\
\text { de águas minerais } \\
\text { comerciais destina- } \\
\text { das ao abastecimen- } \\
\text { to público da cidade } \\
\text { e de poços de } \\
\text { diversas localidades, } \\
\text { quanto à presença } \\
\text { de coliformes totais } \\
\text { e fecais. }\end{array}$ & \begin{tabular}{|c|} 
Foram analisadas \\
amostras de cada tipo \\
(mineral e de abasteci- \\
mento), com base na de- \\
terminação da presença \\
de coliformes totais e \\
fecais. Coletas realizadas \\
em recipientes assépti- \\
cos. As amostras foram \\
incubadas a $35^{\circ} \mathrm{C}$ por \\
24 horas.
\end{tabular} & $\begin{array}{l}\text { Os resultados revelaram que } \\
\text { uma amostra de água mineral e } \\
\text { uma de abastecimento público } \\
\text { apresentaram contaminação } \\
\text { com bactéria do grupo colifor- } \\
\text { me total, } 1 \text { bactéria/ } 100 \mathrm{~mL} \text { de } \\
\text { água. Nenhuma das amostras } \\
\text { de água apresentou contamina- } \\
\text { ção por coliformes fecais. }\end{array}$ & $\begin{array}{c}\text { Rev. } \\
\text { Saúde } \\
\text { Pública }\end{array}$ & Capes \\
\hline $\begin{array}{l}\text { Qualidade micro- } \\
\text { biológica e físico- } \\
\text {-química da água } \\
\text { dos açudes urbanos } \\
\text { utilizados na desse- } \\
\text { dentação animal em } \\
\text { Sobral, Ceará } \\
\text { (MAGALHÂES et } \\
\text { al., 2014) }\end{array}$ & $\begin{array}{l}\text { Avaliar a qualidade } \\
\text { microbiológica e } \\
\text { físico-química da } \\
\text { água dos açudes } \\
\text { urbanos a fim de } \\
\text { conhecer a qualida- } \\
\text { de da água ingerida } \\
\text { pelos animais cria- } \\
\text { dos nas redondezas } \\
\text { desses açudes. }\end{array}$ & $\begin{array}{c}\text { Foram coletadas amos- } \\
\text { tras de água de ambos } \\
\text { os açudes realizando } \\
\text { as seguintes determi- } \\
\text { nações: contagem do } \\
\text { Número Mais Provável } \\
\text { (NMP) de coliformes } \\
\text { totais e termotolerantes, } \\
\text { contagem de aeróbios } \\
\text { mesófilos e identificação } \\
\text { de espécies bacterianas } \\
\text { isoladas das amostras, } \\
\text { pH, alcalinidade, sóli- } \\
\text { dos totais dissolvidos e } \\
\text { temperatura. }\end{array}$ & $\begin{array}{l}\text { Observou-se a presença de co- } \\
\text { liformes totais e termotoleran- } \\
\text { tes, sendo verificada a presença } \\
\text { de Escherichia coli e Yersinia } \\
\text { enterocolitica, que mesmo sendo } \\
\text { indicativos de contaminação } \\
\text { fecal não tornam a água im- } \\
\text { própria para consumo animal, } \\
\text { pois o Número Mais Provável } \\
\text { (NMP) desses microrganis- } \\
\text { mos e contagem de aeróbios } \\
\text { mesófilos encontram-se dentro } \\
\text { do preconizado pela legislação } \\
\text { brasileira. Os valores de pH de } \\
\text { ambos os açudes encontram-se } \\
\text { acima dos valores aceitos pela } \\
\text { legislação, diferentemente } \\
\text { dos valores da quantidade de } \\
\text { sólidos totais dissolvidos, que } \\
\text { estão abaixo do limite máximo } \\
\text { estabelecido. }\end{array}$ & $\begin{array}{l}\text { Revista da } \\
\text { Univer- } \\
\text { sidade } \\
\text { Vale do } \\
\text { Rio Verde }\end{array}$ & Capes \\
\hline
\end{tabular}




\begin{tabular}{|c|c|c|c|c|c|}
\hline Título/Referência & Objetivos & Metodologias & Resultados & Revista & $\begin{array}{c}\text { Base de } \\
\text { dados }\end{array}$ \\
\hline $\begin{array}{l}\text { Qualidade da } \\
\text { água subterrânea } \\
\text { e percepção dos } \\
\text { consumidores em } \\
\text { propriedades rurais } \\
\text { (NUNES et al., } \\
\text { 2010) }\end{array}$ & $\begin{array}{l}\text { Avaliar a água sub- } \\
\text { terrânea das fontes } \\
\text { de abastecimento } \\
\text { utilizadas para } \\
\text { consumo humano } \\
\text { localizadas em } \\
\text { propriedades rurais } \\
\text { sob os aspectos } \\
\text { microbiológicos e } \\
\text { físico-químicos e a } \\
\text { percepção dos con- } \\
\text { sumidores quanto a } \\
\text { sua qualidade. }\end{array}$ & $\begin{array}{l}\text { Para isso, foram cole- } \\
\text { tadas amostras de água } \\
\text { de } 35 \text { poços utilizados } \\
\text { como fonte de abasteci- } \\
\text { mento em } 35 \text { proprieda- } \\
\text { des rurais da região de } \\
\text { Jaboticabal - SP. Para- } \\
\text { lelamente foi aplicado } \\
\text { um questionário para le- } \\
\text { vantamento de aspectos } \\
\text { qualitativos e realizadas } \\
\text { análises físico-químicas, } \\
\text { como: nitrato - pelo } \\
\text { método da redução do } \\
\text { cádmio; turbidez por } \\
\text { turbidimetria, ambas } \\
\text { análises utilizando } \\
\text { o aparelho espectrofo- } \\
\text { tômetro e pH medição } \\
\text { pelo pHmetro. E reali- } \\
\text { zou-se as análises } \\
\text { microbiológicas, como: } \\
\text { coliformes totais, Esche- } \\
\text { richia coli, enterococos e } \\
\text { microrganismos hetero- } \\
\text { tróficos mesófilos. }\end{array}$ & $\begin{array}{l}\text { Os resultados mostraram que } \\
45,7 \% \text { das amostras estavam } \\
\text { fora dos padrões de potabili- } \\
\text { dade quanto a turbidez, } 51,4 \% \\
\text { quanto ao pH e } 42,8 \% \text { quanto } \\
\text { aos parâmetros microbioló- } \\
\text { gicos. A totalidade dos con- } \\
\text { sumidores considerava a água } \\
\text { dos poços de boa qualidade, } \\
\text { baseado nas características } \\
\text { organolépticas, e nenhum } \\
\text { realizava algum processo de } \\
\text { desinfecção, apesar de amostras } \\
\text { estarem impróprias para con- } \\
\text { sumo humano. }\end{array}$ & Nucleus & Capes \\
\hline $\begin{array}{c}\text { Qualidade de água } \\
\text { de dessedentação de } \\
\text { bovinos da fazenda- } \\
\text {-escola do IFRN-I- } \\
\text { panguaçu } \\
\text { (NETO; ARAÚJO; } \\
\text { TÁVORA, 2016) }\end{array}$ & $\begin{array}{c}\text { Diagnosticar a } \\
\text { qualidade da água } \\
\text { que é ofertada para } \\
\text { dessedentação dos } \\
\text { bovinos de leite da } \\
\text { Fazenda-escola do } \\
\text { IFRN. }\end{array}$ & $\begin{array}{l}\text { As coletas e análises } \\
\text { foram realizadas quin- } \\
\text { zenalmente nos bebe- } \\
\text { douros dos bovinos, } 6 \\
\text { bebedouros, durante os } \\
\text { meses de junho a setem- } \\
\text { bro. Os parâmetros ana- } \\
\text { lisados foram: tempera- } \\
\text { tura, } \mathrm{pH} \text {, condutividade, } \\
\text { oxigênio dissolvido e } \\
\text { sólidos totais dissol- } \\
\text { vidos; utilizando uma } \\
\text { sonda multiparamétrica } \\
\text { de qualidade de água. }\end{array}$ & $\begin{array}{c}\text { Os resultados da pesquisa } \\
\text { obtidos revelaram que os parâ- } \\
\text { metros, exceto sólidos totais } \\
\text { dissolvidos, encontraram-se } \\
\text { nos limites aceitáveis pela } \\
\text { legislação, com alguns bebe- } \\
\text { douros apresentando resultados } \\
\text { não aceitáveis. }\end{array}$ & HOLOS & Capes \\
\hline $\begin{array}{l}\text { Qualidade micro- } \\
\text { biológica de água } \\
\text { potável de comu- } \\
\text { nidades urbanas e } \\
\text { rurais, Paraná } \\
\text { (NOGUEIRA et } \\
\text { al., 2002) }\end{array}$ & $\begin{array}{c}\text { Avaliar a qualidade } \\
\text { microbiológica de } \\
\text { amostras de água } \\
\text { tratada e não-tra- } \\
\text { tada } \\
\text { de comunidades } \\
\text { urbanas e rurais e } \\
\text { examinar a relação } \\
\text { entre ocorrência } \\
\text { de coliformes e a } \\
\text { média de tempera- } \\
\text { tura da água. }\end{array}$ & $\begin{array}{l}\text { Foram analisadas } 3.073 \\
\text { amostras de água tra- } \\
\text { tada e não-tratada pelo } \\
\text { método dos tubos múl- } \\
\text { tiplos para determinar o } \\
\text { Número Mais Provável } \\
\text { (NMP) de coliformes } \\
\text { totais e fecais. Destas, } \\
1.594 \text { provenientes de } \\
\text { água de torneiras, } 1.033 \\
\text { de reservatório para } \\
\text { estocar água tratada, } 96 \\
\text { de água de minas e } \\
350 \text { de poços particu- } \\
\text { lares. }\end{array}$ & $\begin{array}{c}\text { O maior número de amostras } \\
\text { contaminadas por coliformes } \\
\text { totais (83\%) e } \\
\text { coliformes fecais ( } 48 \%) \text { foi } \\
\text { observado em água não tratada. } \\
\text { O índice de coliformes totais e } \\
\text { coliformes fecais foi maior nas } \\
\text { amostras de reservatórios do } \\
\text { que nas torneiras ao longo de } \\
\text { sistema de distribuição. Entre } \\
\text { as amostras de água tratada, } \\
\text { foram encontradas bactérias do } \\
\text { grupo coliforme em } 171 \text { dos } \\
1.033 \text { reservatórios amostrados. }\end{array}$ & $\begin{array}{c}\text { Rev. } \\
\text { Saúde } \\
\text { Pública }\end{array}$ & Capes \\
\hline
\end{tabular}




\begin{tabular}{|c|c|c|c|c|c|}
\hline Título/Referência & Objetivos & Metodologias & Resultados & Revista & $\begin{array}{c}\text { Base de } \\
\text { dados }\end{array}$ \\
\hline $\begin{array}{c}\text { Qualidade sanitária } \\
\text { da água distribuída } \\
\text { para abastecimento } \\
\text { público em Rio Ver- } \\
\text { de, Goiás, Brasil } \\
\text { (MORAIS et al., } \\
\text { 2016) }\end{array}$ & $\begin{array}{c}\text { Avaliar a qualidade } \\
\text { da água distribuída } \\
\text { aos habitantes de } \\
\text { três bairros da cida- } \\
\text { de de Rio Verde, em } \\
\text { Goiás. }\end{array}$ & $\begin{array}{c}\text { Foram realizadas qua- } \\
\text { tro coletas semanais nos } \\
\text { dias } 7,14,21 \text { e } 28 \text { do } \\
\text { mês de dezembro de } \\
\text { 2012, em três pontos } \\
\text { selecionados. Foram } \\
\text { realizadas as análises } \\
\text { de sólidos totais dis- } \\
\text { solvidos, turbidez, pH, } \\
\text { coliformes totais e } E \text {. } \\
\text { coli, cloro residual livre. } \\
\end{array}$ & $\begin{array}{l}\text { Todas as amostras atenderam } \\
\text { aos limites determinados pela } \\
\text { referida Portaria com relação } \\
\text { aos parâmetros sólidos totais } \\
\text { dissolvidos, turbidez, pH, } \\
\text { coliformes totais e E. coli. O } \\
\text { sistema de abastecimento de } \\
\text { água analisado apresentou } \\
\text { inconformidade quanto ao } \\
\text { nível de cloro residual livre em } \\
\text { dois bairros. }\end{array}$ & $\begin{array}{c}\text { Cad. } \\
\text { Saúde } \\
\text { Coletiva }\end{array}$ & $\begin{array}{c}\text { SciE- } \\
\text { LO }\end{array}$ \\
\hline $\begin{array}{c}\text { Avaliação da qua- } \\
\text { lidade da água e } \\
\text { percepção higiê- } \\
\text { nico-sanitária na } \\
\text { área rural de Lavras, } \\
\text { Minas Gerais, Bra- } \\
\text { sil, 1999-2000 } \\
\text { (ROCHA et al., } \\
\text { 2006) }\end{array}$ & $\begin{array}{c}\text { Estudar e comparar } \\
\text { a qualidade da água } \\
\text { dos mananciais, } \\
\text { utilizada para } \\
\text { consumo doméstico, } \\
\text { dessedentação de } \\
\text { animais e irriga- } \\
\text { ção de culturas } \\
\text { das propriedades } \\
\text { situadas na zona } \\
\text { rural das sub-bacias } \\
\text { dos ribeirões Água } \\
\text { Limpa e Santa } \\
\text { Cruz, e buscar a } \\
\text { percepção que os } \\
\text { proprietários têm a } \\
\text { respeito da água que } \\
\text { utilizam e os fatores } \\
\text { de risco envolvidos } \\
\text { na contaminação e/ } \\
\text { ou poluição. }\end{array}$ & $\begin{array}{l}\text { Nas propriedades foram } \\
\text { coletadas amostras de } \\
\text { água em cada fonte } \\
\text { utilizada para fins de } \\
\text { consumo doméstico e/ } \\
\text { ou para os animais e/ } \\
\text { ou culturas. Realizou-se } \\
\text { análise de pH, tempera- } \\
\text { tura, oxigênio dissolvido, } \\
\text { cor, turbidez, ferro, } \\
\text { manganês, cloretos, } \\
\text { dureza, e coliformes } \\
\text { fecais. }\end{array}$ & $\begin{array}{l}\text { Grande parte das análises } \\
\text { físico-químicas e microbioló- } \\
\text { gicas estavam fora dos padrões } \\
\text { estabelecidos pela respectiva } \\
\text { legislação. }\end{array}$ & $\begin{array}{c}\text { Cad. } \\
\text { Saúde } \\
\text { Pública }\end{array}$ & $\begin{array}{l}\text { SciE- } \\
\text { LO }\end{array}$ \\
\hline
\end{tabular}

Fonte: Dados da pesquisa, 2017.

Foram analisados 8 artigos dos quais quatro são da Região Sudeste, dois da Região Nordeste, um da Região Sul e um da Região Centro-Oeste do Brasil. Destas 8 produções referente a destinação da água, 62,5\% (5) são para consumo humano, 25\% (2) são de consumo animal e 12,5\% (1) são destinadas ao consumo humano e animal.

Destas, 4 (50\%) realizaram coletas em poços, juntamente com outras fontes, como: torneiras, nascentes, córregos, reservatórios, entre outras, e nas demais produções, foram realizadas coletas em açudes urbanos, água mineral e água de abastecimento, bebedouros de animais, etc. De todas estas amostragens, em sua maioria, a água não está apta para o consumo, ocasionando risco para a saúde humana e animal.

\section{Procedimentos de Coleta e Armazenamento}

Segundo Brandão et al. (2011) apenas uma amostra representa o ambiente estudado como um todo, portanto exige-se conhecimento técnico e científico para procedimentos de coleta, contando com recursos humanos capacitados para realização da atividade em campo. 
Muitas das pesquisas encontradas, os autores não especificaram estritamente os procedimentos realizados para coleta de água. Apenas Morais et al. (2016), Alves, Odorizzi e Goulart (2002), Magalhães et al. (2014) e Nogueira et al. (2003) incluíram em suas pesquisas que as amostras foram coletadas em frascos esterilizados e mantidas em caixas de isopor com gelo até a chegada ao laboratório para análise. Vale ressaltar que, segundo a pesquisa de Nogueira et al. (2003), as amostras de água foram coletadas em frascos contendo Tiossulfato de Sódio, este composto serve para neutralizar a ação do cloro na água (FUNASA, 2013).

\section{Qualidade Microbiológica}

As análises de qualidade microbiológica da água são importantes, sendo exigidas pelas mais diversas legislações aplicadas à utilização da água (BRANDÃO et al., 2011). A análise de contagem padrão de bactérias mesófilas aeróbias evidencia a qualidade microbiológica das etapas do tratamento da água. Embora a maioria das bactérias comuns presentes na água não sejam patogênicas, podem representar risco à saúde, podendo também diminuir a qualidade da água, como por exemplo, odores e sabores desagradáveis (FUNASA, 2013).

Ao analisar-se os artigos selecionados, constatou-se que apenas $3(37,5 \%)$ das pesquisas encontradas estiveram dentro dos padrões exigidos pelas legislações vigentes para as análises microbiológicas, sendo a pesquisa de Morais et al. (2016) para análises de abastecimento público, Magalhães et al. (2014) de dessedentação animal (açudes) e Alves, Odorizzi e Goulart (2002) de análises de abastecimento público e água mineral comercializada. A água mineral natural deve ser livre de parasitas e organismos patogênicos (HUNTER, 1993). As outras 5 (62,5\%) estiveram fora do padrão estipulado pela respectiva legislação.

Amostras coletadas em períodos de chuva nas fontes utilizadas para consumo humano apresentam maior contaminação de microrganismos, como coliformes totais, Escherichia coli, microrganismos mesófilos (AMARAL et al., 2003). Isto, provavelmente, se deve pelo fato de haver escoamento das águas superficiais, que entram em contato com ambientes contaminados e escoam em direção às fontes.

Rocha et al. (2006), Amaral et al. (2003) e Nunes et al. (2010) em suas pesquisas não obtiveram os padrões exigidos pela legislação para análises de coliformes totais e termotolerantes. Em alguns artigos analisados os autores utilizam a terminologia "coliformes fecais". Atualmente essa nomenclatura não é mais utilizada sendo substituída por "coliformes termotolerantes". Os coliformes fecais são bactérias que indicam a predominância de microrganismos do trato intestinal de animais de sangue quente. No entanto, sob altas temperaturas (cujo teste de detecção destes microrganismos é fundamentado) detectam-se não só bactérias de origem fecal, mas também a presença de bactérias não fecais, de vida livre. Por esse motivo passou a ser chamado de "coliformes termotolerantes" (VON SPERLING, 2005). 
Nunes et al. (2010) realizaram análises microbiológicas para detecção de coliformes totais, Escherichia coli e microrganismos mesófilos, porém, esta foi a única pesquisa das 8 encontradas que realizou a análise de Enterococcus. Enterococcus são microrganismos resistentes ao cloreto de sódio e ao $\mathrm{pH}$ alcalino, não há multiplicação de algumas espécies em ambientes aquáticos, apesar de sobreviverem por mais tempos nestes ambientes. Este microrganismo está presente em fezes humanas (APDA, 2012). Apenas 1 artigo não realizou análises microbiológicas (NETO; ARAÚJO; TÁVORA, 2016).

\section{Qualidade Físico-Química}

Em relação à qualidade físico-química, das 8 produções, 3 (37,5\%) não realizaram a investigação frente a estes parâmetros, e das $5(62,5 \%)$ que realizaram, todas fizeram estudos sobre o $\mathrm{pH}$, sendo que 3 estavam em desacordo com os padrões das legislações vigentes, estando 2 acima do permitido e 1 abaixo.

Em relação a saúde pública, valores muito elevados ou muito baixos de $\mathrm{pH}$ podem ocasionar irritações na pele e olhos e em relação ao tratamento de água e abastecimento doméstico, valores alterados podem ocasionar em incrustações nas tubulações e peças de abastecimento, corrosão etc. (VON SPERLING, 2005). O pH é um parâmetro que pode interferir no processo de coagulação-precipitação química durante o tratamento da água, no crescimento microbiano dos sistemas biológicos de tratamento e nos constituintes da alcalinidade e acidez da água (LIMA; GARCIA, 2008).

Quanto à turbidez, dos 3 estudos analisados, 2 (67\%) estavam fora dos padrões, este parâmetro é atribuído à presença de partículas em suspensão, que diminuem a intensidade do feixe de luz ao atravessar a água, pois as partículas que provocam turbidez nas águas são maiores que o comprimento de onda da luz branca (CETESB, 2004).

No estudo de Morais et al. (2016), a análise de cloro residual livre encontrouse abaixo dos valores estipulados pela Portaria n 2914/2011, do Ministério da Saúde (BRASIL, 2011b). Se o teor de cloro residual livre (CRL) não atende ao mínimo exigido, esta água não pode ser considerada como sanitariamente segura para o consumo. Os demais parâmetros analisados, como sólidos totais dissolvidos, $\mathrm{pH}$, condutividade elétrica e turbidez encontraram-se dentro das exigências para este caso específico.

\section{Entrevistas}

Dos 8 artigos analisados, $3(37,5 \%)$ realizaram entrevistas com as pessoas que fazem o uso da água. Em todas as entrevistas os consumidores a consideravam como sendo de boa qualidade, de aspecto bom, obtendo a sensação de pureza, porém, todos 
basearam-se nas características físicas, como a transparência, e as organolépticas, como o sabor e o odor, não avaliando as características sanitárias. Nenhuma destas águas passava pelo processo de desinfecção. Isto se deve provavelmente pelo fato de que essas águas são consumidas a longos períodos sem ter ocorrido problemas visíveis, tais como doenças.

Em uma das entrevistas foi relatado que a água consumida oriunda de poços, apresentava aparentemente mais qualidade, do que a água de abastecimento público, porém, como não realizavam a desinfecção, estavam expostos às doenças de veiculação hídrica.

Nas entrevistas também foram relatadas a existência da realização de uma limpeza superficial e desinfecção dos tanques, porém a maioria nunca fez análises laboratoriais para efetivamente conhecer a qualidade da água que está sendo consumida.

\section{CONCLUSÃO}

Por meio dos artigos analisados, pode-se perceber que existem poucas pesquisas relacionadas com a qualidade físico-química e microbiológica das águas destinadas ao consumo humano e principalmente, ao animal. Frente a esses dados, pode-se perceber que a maioria dos valores das águas analisadas encontravam-se fora dos parâmetros estipulados pelas Resoluções e Portarias vigentes.

\section{REFERÊNCIAS:}

ALVES, N. C., ODORIZZI, A. C., GOULART, F. C. Análise microbiológica de águas minerais e de água potável de abastecimento, Marília, SP. Revista de Saúde Pública, v. 36, n. 6, p. 749-751, 2002. Disponível em: <http://www.scielo.br/pdf/rsp/v36n6/13531.pdf〉. Acesso em: 12 fev. 2017.

AMARAL, L. A. do, et al. Água de consumo humano como fator de risco à saúde em propriedades rurais. Revista de Saúde Pública, v. 37, n. 4. p. 510-514, 2003. Disponível em: <http://www.scielo.br/pdf/rsp/v37n4/16787.pdf>. Acesso em: 10 fev. 2017.

ASSOCIAÇÃO PORTUGUESA DE DISTRIBUIÇÃO E DRENAGEM DA ÁGUA (APDA). Enterococos intestinais. Comissão Especializada de Qualidade da Água, 2012. Disponível em: <http://www.apda.pt/site/ficheiros_eventos/201212041543ft_mb_04 enterococos_intestinais.pdf $>$. Acesso em: 12 abr. 2017.

BACCI, D. C de La; PATACA, E. M. Educação para a água. Estudos Avançados, v. 22, n. 63, p. 211- 226, 2008. Disponível em: <http://www.scielo.br/pdf/ea/v22n63/v22n63a14.pdf>. Acesso em: 05 mar. 2017.

BRANDÃO, C. J., et al. Guia nacional de coleta e preservação de amostras: água, sedimento, comunidades aquáticas e efluentes líquidos. Agência Nacional de Âguas (ANA). Companhia Ambiental do Estado de São Paulo: CETESB, 2011. 327p. Disponível 
em: <http://www.cqa.com.br/arquivos/Guia_Nacional_de_Coleta-CETESB-ANA-2012. pdf>. Acesso em: 15 abr. 2017.

BRASIL. Conselho Nacional do Meio Ambiente (CONAMA). Resolução no 396. Diário Oficial [da] República Federativa do Brasil. Brasília, DF, 03 abr. 2008.

BRASIL. Conselho Nacional do Meio Ambiente (CONAMA). Resolução no 430. Diário Oficial [da] República Federativa do Brasil. Brasília, DF, 16 mai. 2011(a).

BRASIL. Ministério da Saúde (MS). Portaria 2.914. Diário Oficial [da] República Federativa do Brasil. Brasília, DF, 14 dez. 2011(b).

COMPANHIA AMBIENTAL DO ESTADO DE SÃO PAULO (CETESB). Relatório de qualidade das águas interiores do estado de São Paulo, 2003. São Paulo: CETESB, 2004. Disponível em: <http:/www.mpsp.mp.br/portal/page/portal/cao_urbanismo_e_meio_ ambiente/biblioteca_virtual/bv_informativos_tecnicos/Relat\%C3\%B3rio\%20Anual.pdf>. Acesso em: 18 jun. 2017.

FUNDAÇÃO NACIONAL DA SAÚDE (FUNASA). Manual Prático de Análise de Água. 4. ed. - Brasília: 2013. 153p. Disponível em: <http://www.funasa.gov.br/site/wp-content/ files_mf/manual_pratico_de_analise_de_agua_2.pdf >. Acesso em: 17 abr. 2017.

LIMA, W.S.; GARCIA, C.A.B. Qualidade da Água em Ribeirópolis-SE: o Açude do Cajueiro e a Barragem do João Ferreira. Scientia Plena, v.4, n.12, p.1-24, 2008. Disponível em: <https://www.scientiaplena.org.br/sp/article/view/650/314>. Acesso em: 10 mar. 2017.

MAGALHÃES, Y. A., et al. Qualidade microbiológica e físico-química da água dos açudes urbanos utilizados na dessedentação animal em Sobral, Ceará. Revista da Universidade Vale do Rio Verde, v. 12, n. 2, p. 141-148, 2014. Disponível em: <http://periodicos.unincor.br/ index.php/revistaunincor/article/view/1417/pdf_195>. Acesso em: 10 mar. 2017.

MORAIS, W. A., et al. Qualidade sanitária da água distribuída para abastecimento público em Rio Verde, Goiás. Brasil, Caderno de Saúde Coletiva, n. 24, v. 3, p. 361-367, 2016. Disponível em: <http://www.scielo.br/pdf/cadsc/v24n3/1414-462X-cadsc-24-3-361.pdf〉. Acesso em: 10 mar. 2017.

NETO, S. B. N., ARAÚJO, I. I. M., TÁVORA M. A., Qualidade de água de dessedentação de bovinos da fazenda-escola DO IFRN-Ipanguaçu. HOLOS, n. 32, v. 3, p. 52-61, 2016. Disponível em: <http://www2.ifrn.edu.br/ojs/index.php/HOLOS/article/view/4150/1466>. Acesso em: 05 mar. 2017.

NOGUEIRA, G., et al. Microbiological quality of drinking water of urban and rural communities, Brazil. Revista de Saúde Pública, v. 37, n. 2, p. 232-236, 2003. Disponível em: <http://www.scielo.br/pdf/rsp/v37n2/15291.pdf>. Acesso em: 03 mar. 2017.

NUNES, A. P., et al. Qualidade da água subterrânea e percepção dos consumidores em propriedades rurais. Nucleus, v.7, n. 2, p. 95-104, 2010. Disponível em: <http://www.nucleus. feituverava.com.br/index.php/nucleus/article/view/356/512>. Acesso em: Acesso em: 03 mar. 2017. 
ROCHA, M. da, et al. Avaliação da qualidade da água e percepção higiênico-sanitária na área rural de Lavras. Minas Gerais, Brasil, 1999-2000. Caderno de Saúde Pública, v. 22, n.9, p. 1967-1978, 2006. Disponível em: <http://www.scielo.br/pdf/csp/v22n9/21.pdf >. Acesso em: 13 mar. 2017.

VON SPERLING, M. Introdução à Qualidade das Águas e Tratamento de Esgotos. 3. ed. Belo Horizonte: Departamento de Engenharia Sanitária e Ambiental, Universidade Federal de Minas Gerais, 2005. 